Table 1 Isolation of $\mathrm{M}$ hominis from BACTEC Plus/F media

\begin{tabular}{lclll}
\hline \multicolumn{5}{c}{ Days to isolation } \\
\cline { 3 - 5 } Isolate & $\begin{array}{c}\text { Inoculum } \\
(\text { cfu/10 ml) }\end{array}$ & BHI broth & $\begin{array}{l}\text { BACTEC } \\
\text { (aerobic) }\end{array}$ & $\begin{array}{l}\text { BACTEC } \\
\text { (anaerobic) }\end{array}$ \\
\hline $\mathrm{A}$ & 70 & 1 & No growth & 7 \\
$\mathrm{~B}$ & 260 & 1 & No growth & 7 \\
$\mathrm{C}$ & 150 & 1 & No growth & 6 \\
$\mathrm{D}$ & 30 & 1 & No growth & No growth \\
$\mathrm{E}$ & 40 & 1 & No growth & No growth
\end{tabular}

BACTEC (aerobic) $=$ BACTEC Plus Aerobic/F; BACTEC (anaerobic) $=$ BACTEC Plus Anaerobic $/ \mathbf{F}$.

of BACTEC bottles. The subcultures, taken by needle and syringe, were plated onto Columbia blood agar and were incubated anaerobically for 48 hours before examination. The undisturbed BACTEC pairs were terminally subcultured on the seventh day of incubation.

\section{Results}

The five test strains of $M$ hominis grew after incubation for one day in the BHI broth. None of the BACTEC bottles gave a positive growth response-that is, growth was not detected by the fluorescence system during the seven day incubation period. Growth was not detected by daily subculture of the BACTEC Aerobic Plus/F bottles during the incubation period. However, three of the strains grew in the BACTEC Anaerobic Plus/F medium. One strain was detected by subculture after six days' incubation and a further two after seven days' incubation (table 1).

\section{Discussion}

The results of this study are similar to the findings of other investigators ${ }^{146}$ in that $M$ hominis may grow poorly on some blood culture media and this may be attributable to the presence of SPS. Even at sub-bactericidal levels SPS may retard the speed of growth. ${ }^{1}$
Davies and Spencer suggested that the minimum bactericidal concentrations of SPS for $M$ hominis in BHI broth varied between 0.006 and $0.025 \%(\mathrm{w} / \mathrm{v})$. Davis and Eggington ${ }^{6}$ found that $30 \%$ of their $M$ hominis strains were able to grow in the presence of $0.025 \%$ SPS but that no strains were able to grow at $0.05 \%$.

Previous studies relating to $M$ hominis using a variety of BACTEC media and detection systems have shown variable success rates for the isolation of this organism. ${ }^{4-6}$ This present study shows that the BACTEC Aerobic Plus/F medium does not support the growth of this organism. However, the BACTEC Anaerobic Plus/F medium will support the growth of some strains of $M$ hominis when inoculated into $10 \mathrm{ml}$ blood and incubated for seven days.

Becton Dickinson state that a terminal subculture may be necessary to obtain maximum yield of isolates. Our findings support this recommendation and we would suggest that users of the BACTEC 9000 system use a seven day protocol and subculture using appropriate techniques for $M$ hominis, particularly for certain classes of patient-for example, those with postpartum pyrexia.

The authors would like to thank Becton Dickinson UK Limited for the supply of BACTEC media used in this study.

1 Davies S, Spencer RC. Effect of blood culture media on the in vitro recovery of Mycoplasma hominis. F Infect 1988;17:215-20.

2 Al Zahawi MF, Kearns AM, Sprott MS, Joudeh M, Snodgrass CA. A study of three blood culture media for isolating genital mycoplasmas from obstetrical and gynaecological patients. F Infect 1990;21:143-50.

3 Mc Mahon DK, Dummer JS, Pasculle AW, Cassell G. Extragenital Mycoplasma hominis infections in adults. $\mathrm{Am}$ f Med 1990;89:275-81.

4 Kelly VN, Garland SM, Gilbert GL. Isolation of genital mycoplasmas from the blood of neonates and women with pelvic infection using conventional SPS free blood culture pelvic infection using conventional

5 Smaron MF, Boonlayangoor S, Zierdt $\mathrm{CH}$. Detection of Mycoplasma hominis septicaemia by radiometric blood culture. F Clin Microbiol 1985;21:298-301.

6 Davies S, Eggington R. Recovery of Mycoplasma hominis from blood culture media. Med Lab Sci 1991;48:110-13.

\title{
Heat tolerance of vancomycin resistant Enterococcus faecium
}

Department of Microbiology, North Manchester General Hospital, Manchester M8 6RB

Correspondence to: Dr P R Chadwick.
S Panagea, P R Chadwick
(24\%) isolates survived $\left(<5 \log _{10}\right.$ reduction) heat at $65^{\circ} \mathrm{C}$ for 10 minutes. The $E$ faecium isolates were more resistant to heat than the two $E$ faecalis reference strains. No differences in heat tolerance were observed between vancomycin sensitive and resistant strains or between isolates of human or food origin. (F Clin Pathol 1996;49:687-689)

Keywords: Enterococcus faecium, heat, antibiotics, glycopeptide, disinfection methods. 
Table $1 \log _{10}$ reduction in bacterial counts after exposure at different temperature/time parameters

\begin{tabular}{|c|c|c|c|c|c|c|c|c|c|c|c|}
\hline \multirow[b]{3}{*}{ Source } & \multirow[b]{3}{*}{$n$} & \multirow{3}{*}{$\begin{array}{l}\text { Glycopeptide } \\
\text { resistance } \\
\text { phenotype }\end{array}$} & \multicolumn{9}{|c|}{ Number of organisms (\%) } \\
\hline & & & \multicolumn{3}{|c|}{$65^{\circ} \mathrm{C}$ for 10 minutes } & \multicolumn{3}{|c|}{$71^{\circ} \mathrm{C}$ for one minute } & \multicolumn{3}{|c|}{$71^{\circ} \mathrm{C}$ for three minutes } \\
\hline & & & $<5 \log _{10}$ & $5-6 \log _{10}$ & $>6 \log _{10}$ & $<5 \log _{10}$ & $5-6 \log _{10}$ & $>6 \log _{10}$ & $<5 \log _{10}$ & $5-6 \log _{10}$ & $>6 \log _{10}$ \\
\hline Human & 10 & $\operatorname{Van} \mathbf{A} / \mathbf{B}$ & $3(30)$ & $1(10)$ & $6(60)$ & 0 & 0 & $10(100)$ & 0 & 0 & $10(100)$ \\
\hline Human & 9 & Sensitive & $1(11)$ & $4(44.4)$ & $4(44.4)$ & 0 & $1(11.1)$ & $8(88.9)$ & 0 & 0 & $9(100)$ \\
\hline Animal & 8 & VanA & $3(37.5)$ & $3(37.5)$ & $2(25)$ & 0 & 0 & $8(100)$ & 0 & 0 & $8(100)$ \\
\hline E faecalis & 2 & Sensitive & 0 & 0 & $2(100)$ & 0 & 0 & $2(100)$ & 0 & 0 & $2(100)$ \\
\hline Total & 29 & & $7(24.1)$ & $8(27.6)$ & $14(48.2)$ & 0 & $1(3.4)$ & $28(96.5)$ & 0 & 0 & $29(100)$ \\
\hline
\end{tabular}

Enterococci, particularly Enterococcus faecium, are increasingly being isolated from hospitalised patients. The mode of spread has not been fully elucidated; however, recent reports have demonstrated that patient to patient transmission of these organisms, including vancomycin resistant enterococci (VRE), can occur via hands of personnel, contaminated surfaces or patient care equipment. ${ }^{1-3}$ Enterococci are relatively heat tolerant bacteria and there has been concern that some strains may be able to survive the temperature/time parameters currently recommended for disinfection processes. $^{4}$

\section{Methods}

Twenty nine isolates were studied, 27 of which were of $E$ faecium comprising 10 vancomycin resistant clinical isolates (six VanA and four VanB phenotype glycopeptide resistance), eight isolates from uncooked meat (VanA phenotype), and nine vancomycin sensitive isolates from infected patients. Vancomycin sensitive $E$ faecalis reference strains NCTC 775 and ATCC 29212 were also tested. All VRE were considered to be different strains as determined by pulsed field gel electrophoresis (Chadwick PR, unpublished data).

Isolates were cultured in nutrient broth overnight at $37^{\circ} \mathrm{C}$ and held at room temperature for another 24 hours to achieve stationary phase of growth. Viable counts were determined before heating by serial 10 -fold dilutions and culturing $0.1 \mathrm{ml}$ volumes on blood agar plates. Aliquots $(0.1 \mathrm{ml})$ of each culture were added to $0.9 \mathrm{ml}$ sterile water in glass bijoux and the bijoux were incubated in a water bath at $60^{\circ} \mathrm{C}$ for 30 minutes, at $65^{\circ} \mathrm{C}$ for three and 10 minutes, at $71^{\circ} \mathrm{C}$ for one, three and 10 minutes, and at $80^{\circ} \mathrm{C}$ for one, three and 10 minutes. The temperature was monitored in a dummy bijou containing $1 \mathrm{ml}$ sterile water and timing was started after the water in the bijoux had reached the required temperature $\pm 1^{\circ} \mathrm{C}$ (approximately five minutes). Rapid cooling followed exposure at the above temperatures/ holding times and the number of organisms surviving in each bijou was estimated by subculturing $0.1 \mathrm{ml}$ on blood agar plates. The remaining $0.9 \mathrm{ml}$ were added to $9 \mathrm{ml}$ nutrient broth for enrichment. Agar plates were incubated at $37^{\circ} \mathrm{C}$ for 48 hours and the broths were subcultured after 24 hours on blood agar plates. The killing effect was quantified by calculating the $\log _{10}$ reduction in the number of viable organisms before and after exposure to heat. The limit of our detection system was $10 \overparen{\Phi}$ $\mathrm{cfu} / \mathrm{ml}$ nutrient broth.

\section{Results}

Viable counts of initial cultures were found to range from $9 \times 10^{7}$ to $7.5 \times 10^{9} \mathrm{cfu} / \mathrm{ml}$. Complete kill (no viable organisms) was? achieved for all isolates after heating at $71^{\circ} \mathrm{C} \frac{\overrightarrow{0}}{0}$ for 10 minutes and $80^{\circ} \mathrm{C}$ for one, three and $10 \%$ minutes. Three $(10.3 \%)$ isolates were recov- $\infty$ ered after heating at $71^{\circ} \mathrm{C}$ for three minutes, 0 but the reduction in viable count was $>6 \log _{10}$ 글 for one and $>7 \log _{10}$ for the other two. After $>$ heating at $71^{\circ} \mathrm{C}$ for one minute, nine $(31 \%)$ isolates were recovered (two human VanA phenotype, two human VanB phenotype, two of animal origin, and three human vancomycin $屯$ sensitive), but bacterial counts were reduced by $>6 \log _{10}$ for three and by $>7 \log _{10}$ for six.

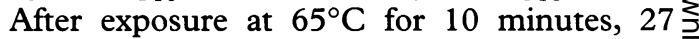
(93.1\%) isolates were recovered (including the two $E$ faecalis strains) and seven showed $<5 \frac{\mathrm{D}}{\circ}$ $\log _{10}$ reduction in viable count. All 29 isolates $\stackrel{\varrho}{\Rightarrow}$ survived heating at $65^{\circ} \mathrm{C}$ for three minutes and at $60^{\circ} \mathrm{C}$ for 30 minutes ( $<5 \log _{10}$ reduction in viable count). No differences were observed between VRE and sensitive strains or between isolates of human and food origin (table 1).? Eleven isolates were tested in duplicate and no을 differences in results were observed.

\section{Discussion}

Enterococci have long been recognised as relatively heat tolerant bacteria, surviving at $60^{\circ} \mathrm{C} \frac{\mathrm{D}}{\mathrm{O}}$ for 30 minutes. Concern has been expressed ${ }^{45}$ that some strains may be able to survive the $N$ temperature/time parameters recommended $N$ by the Department of Health for the disinfection of used and infected linen $\left(65^{\circ} \mathrm{C}\right.$ for 10 O minutes or $71^{\circ} \mathrm{C}$ for three minutes), ${ }^{6}$ or thee British Standard for heat disinfection of bedpan washers $\left(80^{\circ} \mathrm{C}\right.$ for one minute).$^{?}$

None of the isolates in the present study sur- $\frac{7}{0}$ vived exposure to heat at $80^{\circ} \mathrm{C}$ for one minute $\frac{\mathrm{D}}{\mathrm{D}}$ and it is unlikely that washer disinfectors pose $\frac{\rho}{\mathbb{D}}$ a risk of cross infection, provided that they are $\varrho$ used and maintained properly. ${ }^{8}$ Exposure to heat at $71^{\circ} \mathrm{C}$ resulted in a notable reduction in 8 bacterial counts for all isolates $\left(>6 \log _{10}\right)$. Although very low number of organisms wereco recovered from a few strains, we consider such $\rightleftharpoons$ a reduction in viable counts to be effective disinfection. However, the observation that at $65^{\circ} \mathrm{C}$ for 10 minutes, seven $(24.1 \%)$ isolates survived (viable counts were reduced by $<5$ $\log _{10}$ ) raises some concerns about the efficiency of one recommended standard for the 
disinfection of infected linen $\left(65^{\circ} \mathrm{C}\right.$ for 10 minutes). It must be emphasised that our tests assessed the effect of heat in the absence of a cleaning effect, which in practice will very much reduce the load of bacterial contamination. Recent in situ studies failed to demonstrate survival of enterococci in a modern hospital laundry system. ${ }^{9}$ Nevertheless, it may be appropriate to use the higher $\left(71^{\circ} \mathrm{C}\right)$ temperature for the laundry process whenever possible. $E$ faecium isolates were more resistant to heat than the two $E$ faecalis control strains. Overall, we found $E$ faecium isolates to be less heat tolerant than others have suggested. ${ }^{510}$ These differences are almost certainly due to a combination of variations in methodology and interpretation of $\log$ reductions, rather than major strain variations in heat tolerance. These methodologies take no account of the washing effect of medical disinfection processes and we consider that current disinfection guidelines are satisfactory.

Isolates of VRE were provided by Dr B A Oppenheim, Manchester Public Health Laboratory. We thank Dr $\mathrm{H}$ Panigrahi for his support in carrying out this study.
1 Boyce JM, Opal SM, Chow JW, Zervos MJ, Potter-Bynoe G, Sherman CB, et al. Outbreak of multi-resistant Enterococcus faecium with transferable vanB class vancomycin resistance. 7 Clin Microbiol 1994;32:1 148-53.

2 Livornese LL Jr, Dias S, Samel C, Romanowski B, Taylor S, May $\mathrm{P}$, et al. Hospital-aquired infection with vancomycin resistant Enterococcus faecium transmitted by electronic thermometres. Ann Intern Med 1992;117:112-16.

3 Gould FK, Freeman R. Nosocomial infection with microsphere beds. Lancet 1993;342:241-2.

4 Freeman R, Kearns AM, Lightfoot NF. Heat resistance of nosocomial enterococci. Lancet 1994;344:64-5.

5 Kearns AM, Freeman R, Lightfoot NF. Nosocomial enterococci: resistance to heat and sodium hypochlorite. 7 Hosp Infect 1995;30: 193-9.

6 Department of Health and Social Security and the Welsh Office. Hospital Laundry arrangments for used and infected linen. HC(87)30. London: HM Stationery Office 1987. (Renewed until 1993 under letter dated Dec 3, 1992.)

7 Washer disinfectors for medical purposes. BS 2745, part 2 British Standards Institution, 1993.

8 Chadwick PR, Oppenheim BA. Vancomycin-resistant enterococci and bedpan washer machines. Lancet 1994;344:685.

9 Wilcox MH, Jones BL. Enterococci and hospital laundry. Lancet 1995;345:594.

10 Bradley CR, Fraise AP. Abstract P4.2. Second biennial conference of The Federation of Infecton Societies, 1995. $\mathcal{J}$ Infect 1996;32:79.

\title{
The hidden increase in histopathologists' workload
}

\author{
D M Parham
}

\begin{abstract}
The informational content of histopathological reports generated between 1985 and 1995 was assessed. This showed an exponential rise over the past five years. It is postulated that this has arisen from developments in medical science and demands from clinical colleagues. This increase in workload is not addressed by present methods of measurement and has major resource implications.

(F Clin Pathol 1996;49:689-690)
\end{abstract}

Keywords: workload, histopathology.

Histopathologists, like other doctors, are under increasing pressure of work. This includes not only their routine work but also teaching, research, continuing medical education, quality assurance, management, administration, and audit. In histopathology the routine work can be crudely quantified by the number of requests. A more formal unit of measurement is the Welcan system. ${ }^{1}$ This measures the technical requirements in processing the specimen but does not assess a pathologist's input in interpreting or reporting the specimen. This study has examined the increase in the amount of information contained in histopathological reports over the past decade to determine what contribution this has made to the increased workload.

\section{Methods}

In East Dorset there is a combined histopathological department serving Poole and Royal Bournemouth Hospitals. Between 1985 and 1995 histopathological reports for all specimens received at the Royal Bournemouth Hospital during the first two complete weeks (Monday to Friday) in February in selected years were examined. All reports were handwritten by the pathologists prior to typing. The number of items of information recorded were quantified. A point of information included details of the nature of the specimen, measurement, histological description, diagnosis, grade, individual prognostic factors, excision margins, etc. During the weeks of the study in 1985, 1990 and 1992 there were three reporting consultant histopathologists. Two of these subsequently retired and their positions were filled by younger consultants. In 1993 there were four and 1995 five consultant histopathologists.
Accepted for publication 7 May 1996

\section{Department of
Pathology, Royal Hospital, Bournemouth BH7 DW}

